\title{
Exercise may cause myocardial ischemia at the anaerobic threshold in cardiac rehabilitation programs
}

\author{
A.R.C.N. Fuchs ${ }^{1}$, R.S. Meneghelo1, E. Stefanini ${ }^{4}$, A.V. De Paola ${ }^{5}$, P.E.P. Smanio², \\ L.E. Mastrocolla ${ }^{1}$, A.S. Ferraz ${ }^{1}$, S. Buglia1 ${ }^{1}$, L.S. Piegas ${ }^{3}$ and A.A.C. Carvalho ${ }^{4}$ \\ ${ }^{1}$ Serviço de Reabilitação Cardiovascular, ${ }^{2}$ Seção Médica de Medicina Nuclear, ${ }^{3}$ Departamento de Saúde, \\ Instituto Dante Pazzanese de Cardiologia, São Paulo, SP, Brasil \\ ${ }^{4}$ Departamento de Cardiologia, ${ }^{5}$ Departamento de Medicina, Escola Paulista de Medicina, Universidade \\ Federal de São Paulo, São Paulo, SP, Brasil
}

Correspondence to: A.R. Fuchs, R. São Vicente de Paulo, 435, Apto. 32, 01229-010 São Paulo, SP, Brasil

Fax: +55-11-3554-1505. E-mail: rubia.fuchs@hotmail.com

\begin{abstract}
Myocardial ischemia may occur during an exercise session in cardiac rehabilitation programs. However, it has not been established whether it is elicited when exercise prescription is based on heart rate corresponding to the anaerobic threshold as measured by cardiopulmonary exercise testing. Our objective was to determine the incidence of myocardial ischemia in cardiac rehabilitation programs according to myocardial perfusion SPECT in exercise programs based on the anaerobic threshold. Thirty-nine patients (35 men and 4 women) diagnosed with coronary artery disease by coronary angiography and stress technetium-99m-sestamibi gated SPECT associated with a baseline cardiopulmonary exercise test were assessed. Ages ranged from 45 to 75 years. A second cardiopulmonary exercise test determined training intensity at the anaerobic threshold. Repeat gated-SPECT was obtained after a third cardiopulmonary exercise test at the prescribed workload and heart rate. Myocardial perfusion images were analyzed using a score system of 6.4 at rest, 13.9 at peak stress, and 10.7 during the prescribed exercise $(P<0.05)$. The presence of myocardial ischemia during exercise was defined as a difference $\geq 2$ between the summed stress score and summed rest score. Accordingly, 25 (64\%) patients were classified as ischemic and 14 (36\%) as nonischemic. MIBI-SPECT showed myocardial ischemia during exercise within the anaerobic threshold. The $64 \%$ prevalence of ischemia observed in the study should not be looked on as representative of the whole population of patients undergoing exercise programs. Changes in patient care and exercise programs were implemented as a result of our finding of ischemia during the prescribed exercise.
\end{abstract}

Key words: Exercise test; Anaerobic threshold; Myocardial ischemia; Coronary artery disease; Technetium; ${ }^{99 m T c-s e s t a m i b i ~}$

Part of the doctoral dissertation presented by A.R. Fuchs to the Departamento de Cardiologia, Escola Paulista de Medicina, Universidade Federal de São Paulo, São Paulo, SP, Brasil.

Publication supported by FAPESP.

Received March 9, 2008. Accepted January 28, 2009

\section{Introduction}

According to current guidelines, exercise intensity in cardiac rehabilitation programs should not precipitate myocardial ischemia during a training session (1-6). However, it has been shown by SPECT myocardial perfusion imaging that physical exercise within the functional capacity, based on standard exercise stress testing, may cause ischemia, characterized by a reversible perfusion defect, even without angina symptoms or ST-segment depression (7).

With the current widespread use of cardiopulmonary exercise testing, exercise intensity can be defined on the basis of the anaerobic threshold (8-11). At this level of physical exertion, exercise training improves the overall 
functional capacity of the patients and may be applied even to those with coronary artery disease and ventricular dysfunction $(12,13)$. However, it has not yet been established whether exercise intensity determined by anaerobic threshold elicits myocardial ischemia.

Myocardial perfusion studies are more effective in identifying exercise-induced ischemia than other methods used for the diagnosis and risk stratification of obstructive atherosclerotic coronary artery disease (14-16). The objective of this study was to assess the incidence of myocardial ischemia in exercise prescription based on the anaerobic threshold in cardiac rehabilitation programs, using the myocardial perfusion SPECT test.

\section{Material and Methods}

From June 2005 to September 2006, 153 consecutive patients referred to the Nuclear Medicine Department of Instituto Dante Pazzanese de Cardiologia were assessed. All of them showed reversible defect on myocardial perfusion SPECT images and $\geq 70 \%$ diameter stenosis on coronary angiography in at least one of the three main coronary arteries (left anterior descending artery, right coronary artery, left circumflex artery, and their branches). At the initial analysis, 95 patients with at least one of the following characteristics were excluded: age over 75 years, presence of atrial fibrillation, pacemaker, left bundle branch block, preexcitation syndrome, hemodynamically significant valvular heart disease, difficulty in undergoing study procedures appropriately, impossibility to participate in an exercise program after the study, and patients already attending a cardiac rehabilitation program. The remaining 58 patients underwent history taking, clinical examination, and standard 12-lead electrocardiography, in addition to repeat SPECT myocardial perfusion following a cardiopulmonary exercise test using a Medical Graphics $\mathrm{CardiO}_{2}$ system (USA). This was performed without discontinuation of any medication taken regularly. An individualized ramp protocol with a cycle ergometer was used. Criteria for exercise termination were those established by the American College of Cardiology and American Heart Association guidelines (17). A $740 \mathrm{Mbq}$ (or $20 \mathrm{mCi}$ ) amount of technetium-99m-sestamibi ( ${ }^{99 m}$ Tc-sestamibi) was administered to patients weighing $85 \mathrm{~kg}$ or less, and an amount of $0.31 \mathrm{mCi} / \mathrm{kg}$ was administered to those weighing more than $85 \mathrm{~kg}$. The radiotracer was injected at near-maximum heart rate (HR; defined as 220-age) or in the presence of impending exhaustion, exertional ST-segment depression equal to or greater than $0.3 \mathrm{mV}$, or angina pectoris. After the injection, exercise was continued for 30 to $60 \mathrm{~s}$, and myocardial perfusion SPECT was performed 60 min later.
Rest myocardial perfusion SPECT was performed within a week of the first cardiopulmonary exercise test. Under regular medication, only 39 patients showed a persistent reversible defect on myocardial perfusion SPECT images and were eligible for the next phase of the study. Thirty-five of them were men (89\%) and 4 were women (10.3\%). Ages ranged from 45 to 73 years (mean 59.76), and mean body mass index was 28.4 .

The second cardiopulmonary exercise test was similar to the first, but was not associated with myocardial perfusion imaging, and was used to determine the anaerobic threshold using the V-slope method (18). Training level was set at the workload and HR corresponding to the anaerobic threshold. The third cardiopulmonary exercise test was performed at the workload prescribed for tests on mechanically braked bicycles, the same as used in the cardiac rehabilitation program, during over a period of 20 min, corresponding to the continuous aerobic phase of a cardiac rehabilitation program session. The ${ }^{99 \mathrm{~m} T c-s e s t a m i b i}$ dose was injected approximately 19 min into the test, and images were acquired 60 min later.

Both stress and rest SPECT images were processed using the QGS (CEDAR) dedicated software (19). Qualitative and semiquantitative analyses were performed. Radiotracer uptake was compared in 17 segments of the myocardium. Myocardial perfusion images were analyzed by 3 observers blind to patients' data using a score system for each of the 17 segments based on five tomographic views: basal short-axis slice, midventricular short-axis slice, apical short-axis slice, vertical long-axis slice, and horizontal long-axis slice. For each slice, the segment with the highest uptake was graded zero. The remaining segments were graded according to the following criteria: one, mildly reduced uptake; two, moderately reduced uptake; three, severely reduced uptake, and four, absent uptake. For each SPECT image, a summed score was obtained by adding the 17 segmental scores. No difference between the summed stress score and summed rest score indicated absence of stress-induced hypoperfusion, that is to say, absence of ischemia. Myocardial ischemia is defined as a difference $\geq 2$ between stress and rest scores, according to the study by Berman et al. (20), a criterion that has been used in recent landmark studies (21).

Statistical analysis was performed using repeatedmeasures analysis of variance (ANOVA). The Bonferroni multiple comparison test was used to detect differences between cardiopulmonary exercise tests and the scores derived from SPECT images obtained at rest, at peak stress, and during the prescribed exercise. Summed difference score (peak - rest and prescription exercise - rest) were compared by the Wilcoxon test. $P$ values $\leq 0.05$ were 
considered to be statistically significant. All scores for the three situations mentioned above are presented as means and $95 \%$ confidence intervals $(95 \% \mathrm{Cl})$. Mean $\mathrm{HR}$ was compared using the paired Student $t$-test. ST-segment changes between rest, ${ }^{99 m}$ Tc-sestamibi injection at peak stress and prescribed exercise were analyzed by the McNemar test. The Pearson chi-square test or the Fisher exact test was used to determine association among groups with summed difference score $(\geq 2$ and $<2)$ in relation to clinical, angiographic and electrocardiographic data. Age was compared by the Student $t$-test.

The study protocol was approved by the Research Ethics Committees of UNIFESP (Universidade Federal de São Paulo, Escola Paulista de Medicina) and Instituto Dante Pazzanese de Cardiologia, and all patients signed a consent form after being fully informed about the procedures involved in writing.

\section{Results}

The clinical and angiographic characteristics of the patients are shown in Table 1. Coronary angiography revealed significant stenosis involving the left anterior descending artery in 27 patients, the right coronary artery in 25 patients, and the left circumflex artery in 28 patients

The cardiopulmonary variables evaluated in all three cardiopulmonary exercise tests are shown in Table 2.
Table 1. Clinical and angiographic characteristics of the 39 patients who participated in this study.

\begin{tabular}{lc}
\hline Variables & $\mathrm{N}(\%)$ \\
\hline Hypertension & $37(94.9 \%)$ \\
Dyslipidemia & $37(94.9 \%)$ \\
Diabetes mellitus & $18(46.2 \%)$ \\
Smoking & $4(10.3 \%)$ \\
Past smoking & $18(46.2 \%)$ \\
Angina pectoris & $18(46.17 \%)$ \\
Intermittent claudication & $2(5.13 \%)$ \\
Myocardial infarction & $8(20.51 \%)$ \\
Myocardial infarction and CABG and/or PCI & $9(23.07 \%)$ \\
CABG and/or PCI & $12(30.77 \%)$ \\
Uneventful & $10(25.65 \%)$ \\
Aspirin & $35(89.7 \%)$ \\
Beta-blockers & $24(61.5 \%)$ \\
Statins & $34(87.2 \%)$ \\
ACE inhibitors & $30(76.9 \%)$ \\
Vasodilators & $23(59 \%)$ \\
Oral hypoglycemic drugs & $16(41 \%)$ \\
Diuretics & $8(20.5 \%)$ \\
Single-vessel disease & $8(20.5 \%)$ \\
Two-vessel disease & $21(53.9 \%)$ \\
Three-vessel disease* & $10(25.6 \%)$ \\
&
\end{tabular}

$\mathrm{CABG}=$ coronary artery bypass graft surgery; $\mathrm{PCI}=$ percutaneous coronary intervention; $\mathrm{ACE}=$ angiotensin-converting enzyme. *Nine patients underwent revascularization procedures. Of these, 7 were reevaluated later, with failures of at least one graft in 5 and patency identified in 2 .

Table 2. Cardiopulmonary exercise testing (CPET) variables of the 3 tests conducted on 39 patients.

\begin{tabular}{|c|c|c|c|c|}
\hline & 1st CPET & 2nd CPET & 3rd CPET & $\mathrm{P}$ \\
\hline Baseline HR (bpm) & $69.62 \pm 2.32$ & $67.23 \pm 2.14$ & $67.21 \pm 2.49$ & $0.04^{*}$ \\
\hline \multicolumn{5}{|l|}{ Anaerobic threshold } \\
\hline Workload (watts) & $38.46 \pm 4.17$ & $33.57 \pm 2.70$ & $32.87 \pm 2.57$ & \\
\hline HR (bpm) & $90.77 \pm 2.44$ & $89.89 \pm 2.47$ & $90.36 \pm 2.37$ & \\
\hline$\% H R \max$ & $56.32 \pm 1.52 \%$ & $56.12 \pm 1.62 \%$ & $55.92 \pm 1.46 \%$ & \\
\hline $\mathrm{VO}_{2}(\mathrm{~mL} / \mathrm{min})$ & $732.6 \pm 28.61$ & $745.86 \pm 25.16$ & $871.77 \pm 26.43$ & $<0.0001^{*}$ \\
\hline RER & $0.880 \pm 0.010$ & $0.870 \pm 0.010$ & $0.910 \pm 0.020$ & \\
\hline $\mathrm{VO}_{2} / \mathrm{HR}$ & $8.22 \pm 0.33$ & $8.43 \pm 0.35$ & $9.51 \pm 0.32$ & $<0.0001^{*}$ \\
\hline \multicolumn{5}{|l|}{ Peak stress } \\
\hline Workload (watts) & $75.05 \pm 4.23$ & $75.79 \pm 3.62$ & $32.87 \pm 2.56$ & $0.0001^{*}$ \\
\hline $\mathrm{HR}(\mathrm{bpm})$ & $119.2 \pm 2.84$ & $116.03 \pm 2.85$ & $90.36 \pm 2.37$ & $<0.0001^{*}$ \\
\hline$\% H R \max$ & $74.45 \pm 1.78 \%$ & $72.35 \pm 1.77 \%$ & $55.92 \pm 1.46 \%$ & $<0.0001^{*}$ \\
\hline $\mathrm{VO}_{2}(\mathrm{~mL} / \mathrm{min})$ & $1148.15 \pm 40.32$ & $1187.1 \pm 45.11$ & $871.77 \pm 26.33$ & $<0.0001^{*}$ \\
\hline$\%$ Predicted $\mathrm{VO}_{2} \max$ & $52.66 \pm 1.84 \%$ & $53.16 \pm 2.1 \%$ & $40.89 \pm 1.46 \%$ & $<0.0001^{*}$ \\
\hline RER & $1.13 \pm 0.02$ & $1.12 \pm 0.02$ & $0.91 \pm 0.02$ & $<0.0001^{*}$ \\
\hline $\mathrm{VO}_{2} / \mathrm{HR}$ & $9.79 \pm 0.37$ & $10.28 \pm 0.43$ & $9.51 \pm 0.32$ & $0.03^{*}$ \\
\hline
\end{tabular}

Data are reported as means $\pm \mathrm{SEM}$. HR = heart rate $(\mathrm{bpm}) ; \% \mathrm{HRmax}=$ percentage of maximal HR; $\mathrm{VO}_{2}=$ oxygen uptake; $\mathrm{RER}=$ respiratory exchange ratio $\left(\mathrm{VCO}_{2} / \mathrm{VO}_{2}\right) ; \mathrm{VO}_{2} / \mathrm{HR}(\mathrm{mL} / \mathrm{bpm})=$ oxygen pulse; \% predicted $\mathrm{VO}_{2} \mathrm{max}=$ percentage of predicted maximal exercise oxygen uptake. ${ }^{*} \mathrm{P}<0.05$, 3rd CPET compared to 1st CPET and 2nd CPET (ANOVA). 
Baseline cardiopulmonary exercise test for the first myocardial perfusion SPECT

Mean workload achieved was $75.05 \pm 4.23$ watts. Mean HR ranged from $69.62 \pm 2.32 \mathrm{bpm}$ at rest to $119.2 \pm$

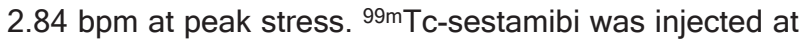
approximately $114.61 \pm 2.70 \mathrm{bpm}$, corresponding to 71.47 $\pm 1.67 \%$ of age-predicted maximal $\mathrm{HR}$ and $52.66 \pm 1.84 \%$ of predicted $\mathrm{VO}_{2}$ max. ST-segment depression $\geq 1 \mathrm{~mm}$ occurred in 20 patients (51.20\%), angina pectoris in 11 $(28.20 \%)$, and intermittent claudication in 1 (2.56\%).

Second cardiopulmonary exercise test for the determination of the level of exercise prescription

The anaerobic threshold was reached at a mean workload of $33.57 \pm 2.70$ watts and mean HR of $89.89 \pm 2.47$ bpm, corresponding to $56.12 \pm 1.62 \%$ of age-predicted maximal HR.

Third cardiopulmonary exercise test during prescribed exercise based on the anaerobic threshold in order to obtain the 2nd myocardial perfusion SPECT

Mean prescribed workload was $32.87 \pm 2.56$ watts. Mean HR during exercise training was $90.36 \pm 2.37 \mathrm{bpm}$, corresponding to $55.92 \pm 1.46 \%$ of age-predicted maximal heart rate and $40.89 \pm 1.46 \%$ of predicted $\mathrm{VO}_{2}$ max. $\mathrm{HR}$ at the time of $99 \mathrm{mTc}$-sestamibi injection was $91.41 \pm 2.38$ bpm, corresponding to $57.01 \pm 1.58 \%$ of age-predicted maximal $\mathrm{HR}$ and $40.89 \pm 146 \%$ of predicted $\mathrm{VO}_{2}$ max. Only 7 patients $(18 \%)$ had ST-segment depression $\geq 1 \mathrm{~mm}$, while 32 patients (82\%) showed no ECG changes. Only 2 patients $(5.12 \%)$ experienced angina pectoris.

\section{Heart rate comparison}

There was a significant difference between $\mathrm{HR}$ at peak stress (114 $\pm 2.70 \mathrm{bpm})$ and prescribed exercise $(91 \pm 2.38$ bpm; $\mathrm{P}=0.001$ ) regarding ${ }^{99 \mathrm{~m} T c-s e s t a m i b i}$ injection, corresponding to $71 \pm 1.67$ and $57 \pm 1.52 \%$ of age-predicted maximal HR, respectively. No differences were found between heart rate at the time of ${ }^{99 \mathrm{mTc}} \mathrm{T}$-sestamibi injection during prescribed exercise ( $91 \pm 2.38 \mathrm{bpm}$ ) and the prescribed HR (90 $\pm 2.37 \mathrm{bpm})$. Peak HR was significantly higher during prescribed exercise than at rest $(67 \pm 2.49$ bpm; $\mathrm{P}<0.0001)$ and was significantly higher $119 \pm 2.84$ bpm than prescribed $\mathrm{HR}(\mathrm{P}<0.0001)$.

\section{Myocardial perfusion SPECT}

Significant differences $(P<0.0001)$ were found between mean scores of SPECT images at rest $(6.44,95 \% \mathrm{Cl}$ $=4.09-8.79)$, peak stress $(13.90,95 \% \mathrm{Cl}=10.48-17.32)$, and prescribed exercise $(10.77,95 \% \mathrm{Cl}=7.69-13.85)$ (Table $3)$. When myocardial ischemia was defined as a difference $\geq 2$ between the summed stress score and summed rest score, the summed difference score was $10.09 \pm 1.40$ at peak exercise and $6.83 \pm 0.99$ during prescription exercise (Table 3). Individual analysis showed that during prescription exercise the summed difference score was $\geq 2$ in 25 (64\%) patients and <2 in 14 (36\%). Among the clinical characteristics considered, namely, prior history of myocardial infarction, prior revascularization, ST-segment depression, and angiographic features, only the latter was significantly different between groups. The incidence of three-vessel disease was greater in the group with a summed difference score $\geq 2$ (Table 4 ).

\section{Discussion}

Among the several methods used to prescribe exercise intensity for coronary artery disease patients, cardiopulmonary exercise testing to determine the anaerobic threshold has come to the forefront, not only because of its widespread availability but also because it is an extremely valuable tool for risk stratification of patients with congestive heart failure at tertiary cardiac centers. In post-myocardial infarction patients receiving beta-blockers, the anaerobic threshold has been considered to be a "gold standard" for exercise prescription (22). The use of the V-slope method to determine training intensity is individualized, since it depends on patient age and fitness level. It is

Table 3. Summed stress score (SSS), summed difference score (SDS) peak/prescription exercise, summed rest score for 39 patients.

\begin{tabular}{lrrr}
\hline Score (1) vs (2) & Mean (median) \pm SEM (1) & Mean (median) \pm SEM (2) & P \\
\hline SSS peak vs summed rest score & $13.90(12) \pm 1.69$ & $6.44(4) \pm 1.16$ & $<0.0001^{\mathrm{t}}$ \\
SSS prescription exercise vs summed rest score & $10.77(9) \pm 1.52$ & $6.44(4) \pm 1.16$ & $<0.0001^{\mathrm{t}}$ \\
SSS peak vs SSS prescription exercise & $13.90(12) \pm 1.69$ & $10.77(9) \pm 1.52$ & $<0.0001^{\mathrm{t}}$ \\
SDS peak vs SDS prescription exercise & $7.46(5) \pm 1.00$ & $4.33(2) \pm 0.76$ & $<0.0001^{\mathrm{w}}$ \\
SDS peak - SDS prescription exercise $(\geq 2)$ & $10.09(9) \pm 1.40$ & $6.83(6) \pm 0.99$ & $0.003^{\mathrm{w}}$
\end{tabular}

Data are reported as means \pm SEM and median. $\mathrm{P}<0.05$ (statistically significant difference between groups). $t=t$-test; $w=W i l c o x o n$ test. 
submaximal and predominantly aerobic, allowing exercises to be performed for prolonged periods (23). The anaerobic threshold has the advantage of being independent of patient motivation and thus more objective and reproducible than maximal oxygen uptake $(23,24)$. However, it has not been established whether this type of prescription is sufficiently safe according to current guidelines, which recommend that exercise should be prescribed for patients with coronary artery disease at a level that does not elicit myocardial ischemia, characterized by angina pectoris and/or ST-segment depression (2).

The present study is justified because exercise intensity immediately below the ischemic threshold has been proven to produce myocardial ischemia, as measured by SPECT scanning $(7,25)$. This may be accomplished by clinical and electrocardiographic monitoring of the rehabilitation session. Yet, in some conditions such as post-acute myocardial infarction, ventricular hypertrophy, and previous ST-segment changes, among others, myocardial perfusion SPECT permits a more accurate identification of the presence of myocardial ischemia during a cardiac rehabilitation program. This method was used in the present study because of its diagnostic superiority.

Although they did not constitute a homogeneous group, the patients included in the present study had coronary artery disease previously documented by coronary angiography. Thirty-one (79.5\%) had at least two-vessel disease and $8(20.5 \%)$ had single-vessel disease, but with at least $70 \%$ stenosis, justifying the presence of reduced uptake on stress images.

All 39 patients had stable angina or were asymptomatic and were being medically treated by their cardiologists based on clinical and angiographic criteria. These characteristics make these patients similar to those referred for supervised rehabilitation. It can be noted that the group of 39 patients studied was significantly smaller than the initial sample of 153 selected among patients routinely treated at the Department of Nuclear Cardiology of our institution. This may be explained by the need to exclude all patients in whom ST-segment interpretation would be impaired by their baseline conditions. In a Tertiary Center of Nuclear Cardiology, an elevated number of patients are referred for myocardial perfusion SPECT exactly because they cannot be properly assessed by standard exercise stress testing. Another reason for exclusion was patient difficulty in attending a rehabilitation program.

By performing qualitative and semiquantitative SPECT analyses, we could minimize potential biases associated with qualitative interpretation alone. The use of a summed difference score equal to or greater than 2 followed the recommendations of the studies that introduced this technique (21).

Recently, a summed difference score of 2 was considered to be indicative of myocardial ischemia in the COURAGE trial (21), a large multicenter study highly influential among cardiologists. Therefore, the summed difference

Table 4. Clinical, angiographic and electrocardiographic data according to summed difference score in exercise prescription for 39 patients.

\begin{tabular}{lccc}
\hline & Group A ( $\geq 2)$ & Group B (<2) & P \\
\hline Number & $25(64 \%)$ & $14(36 \%)$ & \\
Age (years) & $60.4 \pm 7.37$ & $58.64 \pm 8.22$ & $0.497^{\mathrm{f}}$ \\
Hypertension & $24(96 \%)$ & $13(92.9 \%)$ & $0.676^{f}$ \\
Dyslipidemia & $25(67.6 \%)$ & $12(32.4 \%)$ & $0.120^{f}$ \\
Diabetes mellitus & $12(48 \%)$ & $6(42.9 \%)$ & $0.757^{p}$ \\
Smoking & $3(12 \%)$ & $1(7.1 \%)$ & $0.870^{f}$ \\
Past smoking & $11(44 \%)$ & $7(5 \%)$ & $0.870^{f}$ \\
Angina pectoris & $1(4 \%)$ & $1(7.1 \%)$ & 1.000 \\
Myocardial infarction & $12(48 \%)$ & $5(35.7 \%)$ & $0.458^{p}$ \\
Myocardial infarction and coronary artery bypass graft & $7(28 \%)$ & $2(14.3 \%)$ & $0.330^{f}$ \\
$\quad$ surgery and/or percutaneous coronary intervention & & & \\
Coronary artery bypass graft surgery & $3(12 \%)$ & $3(21.4 \%)$ & $0.647^{f}$ \\
$\quad$ and/or percutaneous coronary intervention & & & \\
Single-vessel disease & $2(8 \%)$ & $5(35.7 \%)$ & $0.075^{f}$ \\
Two-vessel disease & $14(56 \%)$ & $8(57.1 \%)$ & $0.945^{f}$ \\
Three-vessel disease & $9(36 \%)$ & $1(7.1 \%)$ & $0.048^{f *}$ \\
ST-segment depression $=1 \mathrm{~mm}$ & $6(24 \%)$ & $0 \%$ & $0.139^{f}$ \\
ST-segment depression $>1$ mm & - & $1(7 \%)$ & $0.359^{f}$ \\
\hline
\end{tabular}

Myocardial ischemia is defined as a difference $\geq 2$ between the summed stress score and the summed rest score. ${ }^{*} \mathrm{P}<0.05 . \mathrm{t}=t$-test; $\mathrm{f}=$ Fisher exact test; $\mathrm{p}=$ Pearson chi-square test. 
score $\geq 2$ found here in 25 patients (64\%) suggests the presence of exercise-induced myocardial ischemia. Although the accuracy of SPECT imaging was not specifically evaluated in the present study, this had already been done in a previous study performed at our institution, showing a high degree of agreement among interpretations $(k=0.810)(26)$. Based on the difference between the summed stress score and summed rest score, myocardial ischemia, as measured by SPECT perfusion studies, has been quantified as follows: $0-1=$ no ischemia; $2-6=$ mild-to-moderate ischemia, and $>6=$ severe ischemia (COURAGE). According to these criteria, 14 patients (35.89\%) had no ischemia, 15 (38.47\%) had mild-to-moderate ischemia, and 10 (25.64\%) had severe ischemia. One-fourth of our patients, therefore, had severe ischemia, suggesting that these patients should have their clinical and electrocardiographic parameters monitored during the first sessions of a rehabilitation program. No significant differences were found regarding age or clinical, angiographic, and electrocardiographic data of patients with a summed difference score $\geq 2$ and $<2$, except for the presence of three-vessel disease $(P=0.048$; Table 4). Perhaps these patients would be candidates for a more thorough clinical evaluation. Patients with myocardial ischemia documented by myocardial SPECT were prescribed workloads below their anaerobic threshold and referred to a special program consisting of interval training during all aerobic phases of rehabilitation. Alternatively, these patients were prescribed muscular resistance exercise at about $40 \%$ of maximal contraction, for complementation.

The objective of this study was not to recommend the routine use of myocardial perfusion SPECT to evaluate the accuracy of exercise prescription in rehabilitation programs, but rather to open the possibility of using nuclear medicine to assess the degree of ischemia induced by regular rehabilitation exercises in selected patients.

Limitations: this study was conducted at a single center on a small number of patients, and the female gender was underrepresented. The study sample was a convenience sample, i.e., it was composed of patients with ischemic heart disease due to diffuse, extensive atherosclerotic disease recruited from a tertiary center, and should not be considered to be representative of the larger universe of patients with ischemic heart disease for whom supervised exercise programs are indicated.

Clinical implications: our results suggest that, in supervised exercise training programs, exercise prescription based on the anaerobic threshold is still recommended for coronary artery disease with stress-induced myocardial ischemia. Nevertheless, because myocardial ischemia may be present, the presence of ST-segment depression and angina pectoris should determine a reduction in exercise intensity. These recommendations are valid, even after publication of the study by Noel et al. (27), which did not find significant changes in the course of only 11 patients in the presence of ST-segment depression of $1 \mathrm{~mm}$. In patients with diffuse and severe coronary artery disease, myocardial perfusion SPECT may be a useful adjunct for a more appropriate and accurate detection of ischemia, since it enables exercise to be prescribed more safely below the ischemic zone, regardless of the anaerobic threshold.

Based on our results, the following conclusions can be drawn: in patients with ischemic heart disease due to severe, diffuse atherosclerosis, myocardial ischemia was detected by ${ }^{99 m}$ Tc-sestamibi myocardial perfusion SPECT during the continuous aerobic phase prescribed based on the anaerobic threshold, even in clinically stable patients. Angina pectoris and/or ischemic ECG changes have low sensitivity to identify myocardial ischemia during the aerobic phase of a cardiac rehabilitation session. The $64 \%$ prevalence of ischemia observed in the study should not be considered representative of the entire population of patients undergoing an exercise program. The changes in patient care and exercise program were implemented as a result of our findings (ischemia during the prescribed exercise).

\section{References}

1. Fletcher GF, Balady GJ, Amsterdam EA, Chaitman B, Eckel $\mathrm{R}$, Fleg J, et al. Exercise standards for testing and training: a statement for healthcare professionals from the American Heart Association. Circulation 2001; 104: 1694-1740.

2. American College of Sports Medicine. Guidelines for exercise testing and prescription. 7th edn. Philadelphia: J.B. Lippincott; 2007.

3. Gaziano JM, Manson JE, Ridker PM. Primary and secondary prevention of coronary heart disease. In: Zipes DP,

Libby P, Bonow RO, Braunwald E (Editors), Braunwald's heart disease. 7th edn. Philadelphia: Elsevier/Saunders; 2005. p 1057-1081.

4. King ML, Williams MA, Fletcher GF, Gordon NF, Gulanick $\mathrm{M}$, King CN, et al. Medical director responsibilities for outpatient cardiac rehabilitation/secondary prevention programs: a scientific statement from the American Heart Association/ American Association for Cardiovascular and Pulmonary Rehabilitation. Circulation 2005; 112: 3354-3360. 
5. Leon AS, Franklin BA, Costa F, Balady GJ, Berra KA, Stewart KJ, et al. Cardiac rehabilitation and secondary prevention of coronary heart disease: an American Heart Association scientific statement from the Council on Clinical Cardiology (Subcommittee on Exercise, Cardiac Rehabilitation, and Prevention) and the Council on Nutrition, Physical Activity, and Metabolism (Subcommittee on Physical Activity), in collaboration with the American Association of Cardiovascular and Pulmonary Rehabilitation. Circulation 2005; 111: 369-376.

6. Thompson PD, Franklin BA, Balady GJ, Blair SN, Corrado D, Estes NA III, et al. Exercise and acute cardiovascular events placing the risks into perspective: a scientific statement from the American Heart Association Council on Nutrition, Physical Activity, and Metabolism and the Council on Clinical Cardiology. Circulation 2007; 115: 2358-2368.

7. Meneghelo RS, Magalhaes HM, Smanio PE, Fuchs AR, Ferraz AS, Buchler RD, et al. Evaluation of prescription of exercise, for rehabilitation of coronary artery disease patients by myocardial scintigraphy. Arq Bras Cardiol 2008; 91: 223-251.

8. Gordon NF, Scott CB. Exercise intensity prescription in cardiovascular disease. Theoretical basis for anaerobic threshold determination. J Cardiopulm Rehabil 1995; 15: 193-196.

9. Arena R, Myers J, Williams MA, Gulati M, Kligfield P, Balady GJ, et al. Assessment of functional capacity in clinical and research settings: a scientific statement from the American Heart Association Committee on Exercise, Rehabilitation, and Prevention of the Council on Clinical Cardiology and the Council on Cardiovascular Nursing. Circulation 2007; 116: 329-343.

10. Gibbons ES. The significance of anaerobic threshold in exercise prescription. J Sports Med Phys Fitness 1987; 27: 357-361.

11. Vivacqua RCC. Ergoespirometria. In: Vivacqua RCC, Carreira MAMQ (Editors), Ergometria, ergoespirometria, cintilografia e ecocardiografia de esforço. São Paulo: Atheneu; 2007. p 125-153.

12. Ferrand-Guillard C, Ledermann B, Kotzki N, Benaim C, Givron $\mathrm{P}$, Messner-Pellenc $\mathrm{P}$, et al. Is it necessary to rehabilitate coronary artery disease patients based on ventilatory threshold? Ann Readapt Med Phys 2002; 45: 204-215.

13. Bussotti M, Apostolo A, Andreini D, Palermo P, Contini M, Agostoni P. Cardiopulmonary evidence of exercise-induced silent ischaemia. Eur J Cardiovasc Prev Rehabil 2006; 13: 249-253.

14. Hachamovitch R, Berman DS. The use of nuclear cardiology in clinical decision making. Semin Nucl Med 2005; 35: 62-72.

15. Brindis RG, Douglas PS, Hendel RC, Peterson ED, Wolk $\mathrm{MJ}$, Allen JM, et al. ACCF/ASNC appropriateness criteria for single-photon emission computed tomography myocardial perfusion imaging (SPECT MPI): a report of the American College of Cardiology Foundation Quality Strategic Directions Committee Appropriateness Criteria Working Group and the American Society of Nuclear Cardiology endorsed by the American Heart Association. J Am Coll Cardiol 2005; 46: 1587-1605.
16. Klocke FJ, Baird MG, Lorell BH, Bateman TM, Messer JV, Berman DS, et al. ACC/AHA/ASNC guidelines for the clinical use of cardiac radionuclide imaging - executive summary: a report of the American College of Cardiology/American Heart Association Task Force on Practice Guidelines (ACC/AHA/ASNC Committee to Revise the 1995 Guidelines for the Clinical Use of Cardiac Radionuclide Imaging). J Am Coll Cardiol 2003; 42: 1318-1333.

17. Gibbons RJ, Balady GJ, Bricker JT, Chaitman BR, Fletcher GF, Froelicher VF, et al. ACC/AHA 2002 guideline update for exercise testing: summary article. A report of the American College of Cardiology/American Heart Association Task Force on Practice Guidelines (Committee to Update the 1997 Exercise Testing Guidelines). J Am Coll Cardiol 2002; 40: 1531-1540.

18. Beaver WL, Wasserman K, Whipp BJ. A new method for detecting anaerobic threshold by gas exchange. J Appl Physiol 1986; 60: 2020-2027.

19. Germano G, Erel J, Lewin H, Kavanagh PB, Berman DS. Automatic quantitation of regional myocardial wall motion and thickening from gated technetium-99m sestamibi myocardial perfusion single-photon emission computed tomography. J Am Coll Cardiol 1997; 30: 1360-1367.

20. Berman DS, Kang X, Van Train KF, Lewin HC, Cohen I, Areeda $\mathrm{J}$, et al. Comparative prognostic value of automatic quantitative analysis versus semiquantitative visual analysis of exercise myocardial perfusion single-photon emission computed tomography. J Am Coll Cardiol 1998; 32: 19871995.

21. Shaw LJ, Heller GV, Casperson P, Miranda-Peats R, Slomka P, Friedman J, et al. Gated myocardial perfusion single photon emission computed tomography in the clinical outcomes utilizing revascularization and aggressive drug evaluation (COURAGE) trial, Veterans Administration Cooperative study No. 424. J Nucl Cardiol 2006; 13: 685-698.

22. Chaloupka V, Elbl L, Nehyba S, Tomaskova I, Jedlicka F. Exercise intensity prescription after myocardial infarction in patients treated with beta-blockers. J Cardiopulm Rehabil 2005; 25: 361-365.

23. Wasserman K, Hansen JE, Sue DY, Stringer WW, Whipp BJ. Principles of exercise testing and interpretation, including pathophysiology and clinical applications. 4th edn. Philadelphia: Lippincott Williams \& Wilkins; 2005.

24. Singh VN. The role of gas analysis with exercise testing. Prim Care 2001; 28: 159-179.

25. Milani M. Avaliação da prevalência e do significado funcional da isquemia miocárdica quantificada pela cintilografia de esforço antes e após a reabilitação cardiovascular. [Doctoral thesis]. Ribeirão Preto: Faculdade de Medicina de Ribeirão Preto, USP; 2007.

26. Smanio PE, Carvalho AC, Tebexreni AS, Thom A, Rodrigues $F$, Meneghelo $R$, et al. Coronary artery disease in asymptomatic type-2 diabetic women. A comparative study between exercise test, cardiopulmonary exercise test, and dipyridamole myocardial perfusion scintigraphy in the identification of ischemia. Arq Bras Cardiol 2007; 89: 263-267.

27. Noel M, Jobin J, Marcoux A, Poirier P, Dagenais GR, Bogaty $P$. Can prolonged exercise-induced myocardial ischaemia be innocuous? Eur Heart J 2007; 28: 1559-1565. 